\title{
Improving Academic Success Through Applied Learning Theories, A General Elective (GE) Course
}

\author{
O A P Tulabut ${ }^{1}$, R S Mangalus ${ }^{2}$, R N C Cruz ${ }^{3}$, A B Gonzales ${ }^{4}$, E L L Pare ${ }^{5}$, I M C \\ Evaristo $^{6}$, and C L M De $\mathrm{Ala}^{7}$ \\ \{gonzales.abigail@auf.edu.ph\}
}

Angeles University Foundation, MacArthur Highway, Angeles, 2009 Pampanga, Philippines

\begin{abstract}
Traditional schools often link academic success with academic achievement identifying General Weighted Average as an essential indicator. More recently, however, educators have become interested in exploring the role of psychological constructs such as well-being and student engagement in academic success. The present student took a similar path by determining whether a newly designed General Education elective course for freshmen dubbed as Applied Learning Theories correlates with academic achievement, student engagement and well-being. Unlike most introductory and study skills courses, ALT is contextualized and integrates not only study strategies and test-taking attributes but also self-care practices. The course was structured to build transferable learning skills that will have a long-term impact on engagement, retention, graduation rates, and general wellbeing. Some of the course topics are managing procrastination, metacognitive learning strategies, achieving a growth mindset, self-management skills, and practicing self-care. Results showed that as students learn and engage in the subject, they appear to become more academically and cognitively engaged and competent. With the introduction of such concepts, students were able to develop positive emotions, sustain interest in challenging tasks, and find meaning and purpose in their academic pursuits while increasing their chances of academic success.
\end{abstract}

Keywords: academic success, applied learning theories, GE Course.

\section{Introduction}

Higher Educational Institutions play an important role in shaping academic success, especially that it is a metric for an institutions' performance. Most often, educational systems equate academic success with academic achievement. However, York, Gibson, and Rankin [38] argued the ambiguity of academic success, mainly due to its "amorphous nature." Their definition of academic success includes academic achievement, attainment of learning objectives, acquisition of desired skills and competencies, satisfaction, persistence, and postcollege performance [38]. Traditional education gives credence to these factors in preparing students for future productivity. However, more recently, scholars have looked into psychological constructs that can promote academic success [7], such as well-being and student engagement.

University students have been considered an at-risk population since common behavior problems such as drug and alcohol use, internet addiction, and violence are associated with the age at which students start in College [30, 39]. Mental disorders such as anxiety, mood, and substance abuse, usually peak around adolescence to early adulthood [22]. These behavior 
problems are due to various stressful experiences ranging from academic pressure, separation from family, individuation, relationship problems to work responsibilities [30]. Universities need to put a premium on enhancing protective factors such as well-being to help students overcome any distress that may impact academic success.

Well-being is a well-researched concept in psychology and has been found to have impressive and meaningful consequences. Martin Seligman identified five building blocks that enable humans to flourish, and these are positive emotions, engagement, relationships, meaning, and accomplishments [32]. Interestingly, trends in positive psychology have overflowed into education. It posits that schools should teach not only the skills of achievement but also skills of well-being, how to live healthy, purposeful, and meaningful lives [4, 33]. Seligman [33] elaborated that well-being is synergistic with better learning. More specifically, if students know how to tap into positive emotions, are capable of experiencing flow, proficient in cultivating positive relationships, engaging in activities bigger than themselves, and identifying clear goals, they can learn better and, therefore, be academically successful. More specifically, positive emotions broaden the scope of attention [17], induce efficiency in decision making, affect cognition, and increase learning outcomes [35]. In general, researches have shown that students with positive well-being are more likely to perform better and complete their studies $[11,39]$.

Equally important is student engagement, which has been identified as a construct essential to learning. It is manifested when students remain motivated to perform at optimal levels to maximize their competencies. Student engagement is a students' behavioral, cognitive, and emotional connection to learning [16]. Kahu developed a holistic framework of student engagement that depicted the antecedents and consequences of the interplay between student and institutional factors against the bigger socio-political context where students, faculty, and institutions are situated [21]. The framework was refined to include student experiences that occur in an educational interphase. The four elements in the interphase are self-efficacy, belonging, emotions, and well-being, stemming from the interaction between the students and the Institution [20].

Another student engagement model describes four facets: (1) Academic engagement, which refers to behaviors that directly contribute to academic achievement such as accomplishing homework and listening attentively in class; Social engagement, which involves mandated and nonmandated social behaviors that facilitate learning, such as following classroom rules and actively interacting with teachers and classmates in productive ways; 3) Cognitive engagement, which indicates behaviors that involve effortful and critical thinking for complex learning, such as advance reading and clarifying questions more comprehensively; and 4) Affective engagement, which deals with student involvement in programs that help them learn but also gain a greater sense of belongingness in school, such as joining extracurricular activities and participating in community extension project This multidimensional construct prevents poor student outcomes and has been found to have a positive relationship with academic performance $[18,26]$.

Higher education is responsible for meeting society's learning needs and allowing students to have avenues to be academically successful [12]. This responsibility is the latent intention of the Philippines ' shift to K-12 education a few years ago. The K-12 curriculum serves as a more efficient teaching system that encourages student engagement, academic achievement, and "real-world" preparedness due to a more focused learning specialization than a congested general curriculum like the old Basic Education Curriculum (BEC). However, opinions on K12 vary from ambivalence to acceptance [2], affecting different sectors in the country [1].

This educational reform also necessitated the creation of the College Readiness Standards (CRS) by the Commission on Higher Education (CHED). The CRS represents higher 
education's intention to share with basic education the expectations for college learning [34]. This way, it assured that graduates of the $\mathrm{K}$ to 12 program would not need any remediation in entry-level undergraduate courses. On the contrary, research showed that senior high school graduates were less effective than BEC graduates in readiness and performance despite perceiving the K-12 curriculum as a positive development [36]. This finding affirmed what research documented about college eligibility not being synonymous with college readiness $[3$, $8,19,24]$.

Research has documented several ways to bridge this gap. To improve first-year college success outcomes, Universities offer multi-level initiatives to include orientation programs, optional introductory learning and study skills courses, first-year seminars, freshmen interest groups, and mentoring or coaching programs [31]. Hunter and Linder [15], as cited by Culver and Bowman [15], described that more often, scholars categorized these freshmen educational practices into either a (1) orientation and academic success seminars that provide resources to ensure ease of transition to college life or (2) academic inquiry-based seminars that practice metacognitive strategies in academic topics based on students or faculty interests. These practices are considered by the Association of American Colleges and Universities as "highimpact" and correlate with student performance [9]. However, there are mixed results regarding these practices' effectiveness for predicting college success and retention [15]. In addition, each program's activities lead to different psychological outcomes that purportedly lead to increases in academic and social integration, eventually leading to student retention [6].

To respond to society's changing learning needs and improve academic success among its freshmen students, Angeles University Foundation designed a General Education elective course, Applied Learning Theories (ALT), an orientation and academic success course. The subject was designed in part on freshmen study skill courses anchored on research-based learning strategies [19]. Unlike most introductory and study skills courses, ALT is contextualized and integrates not only study strategies and test-taking attributes but also selfcare practices. Starting Academic Year 2019-2020, all freshmen were required to take this threeunit subject. The course is structured to build transferable learning skills that will have a longterm impact on engagement, retention, graduation rates, and general well-being. Some of the course topics are managing procrastination, metacognitive learning strategies, achieving a growth mindset, self-management skills, practicing self-care, and stress management.

The present study aims to determine whether ALT can predict academic success over time. ALT's contextualized nature, which is a blend of academic and non-academic correlates of academic performance, gives rise to the question of how effective it is in predicting academic achievement, student engagement, and well-being. The study's findings will be a basis for datainformed decisions towards providing students with opportunities to develop, learn, and succeed wholly. The following are the specific objectives of the first phase of the study:

1. Determine if engagement in Applied Learning Theories (ALT) is significantly associated with academic achievement.

2. Determine if engagement in Applied Learning Theories (ALT) is significantly associated with overall student engagement.

3. Determine if engagement in Applied Learning Theories (ALT) is significantly associated with psychological well-being. 


\section{Method}

\subsection{Research Design}

This paper reports a preliminary analysis of the five (5) phase longitudinal, explanatory study illustrated in Figure 1. This study tests whether engagement in Applied Learning Theories is associated with academic success, psychological well-being, and student engagement. Likewise, data are collected during the Academic Year 2019-2020, the first year of the Applied Learning Theories (SSELECT) course.

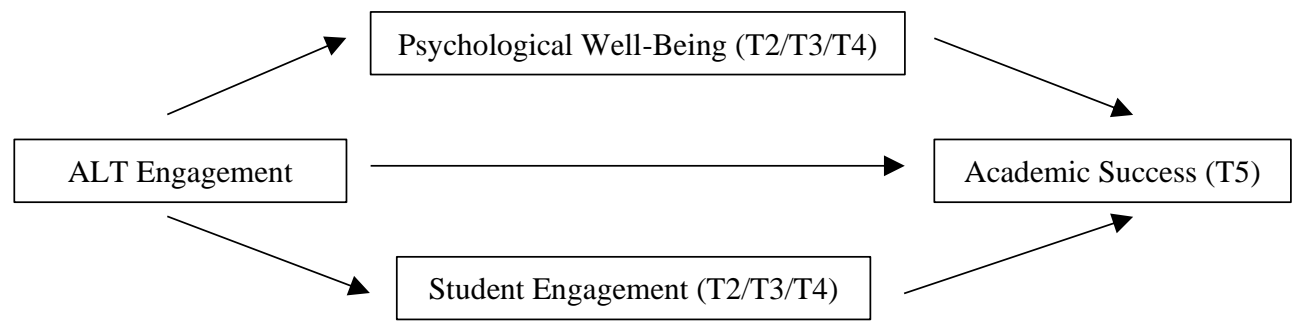

Figure 1. Improving academic success through ALT Engagement as mediated by psychological well-being and student engagement

\subsection{Participants}

The participants of the study were students enrolled in Applied Learning Theories (SSELECT) during the Academic Year (A.Y.) 2019-2020. They were recruited through their respective class instructors. A total of 1066 students completely answered all administered research instruments. These students will be followed to the expected completion of their undergraduate degree by A.Y. 2022-2023.

\subsection{Research Instruments}

\subsubsection{Academic Success}

Academic success was operationalized in Phase 1 of the study using the general weighted average (GWA). The final GWAs of students during the semester in which they are enrolled in the Applied Learning Theories (SSELECT) class will be requested from the Office of the University Registrar at the end of the academic year. Subsequently, measures of academic success will include retention rates, acquisition of desired skills and competencies, satisfaction, and employability.

\subsubsection{Psychological Well-Being}

The PERMA Profiler (PERMA) was used to examine psychological well-being. It is a 23item scale measuring five psychological well-being domains: positive emotions, engagement, relationships, meaning, and accomplishment. The scale ranges from 0 suggesting "never", 
"terrible", and "not at all" to 10 implying "always", "excellent", and "completely". An example of a measure item is "How much of the time do you feel you are making progress towards accomplishing your goals?" The scale appears to have sound psychometric properties with a Cronbach's alpha ranging from .71 to .89 with evidence of convergent and divergent validity [10].

\subsubsection{Academic Success Student Engagement}

The University Student Engagement Inventory (USEI) was used to measure student engagement. According to Maroco et al. [27], it is a 15-item scale conceptualized as a secondorder factor reflected by behavioral, cognitive, and emotional dimensions. The 5-point Likert scale ranges from 1 , which is "never," to 5, which corresponds to a frequency of "always." The scale's psychometric properties are also acceptable, with a study obtaining a Cronbach's alpha of .80 with evidence suggesting sound convergent and divergent validity [5].

\subsubsection{ALT Engagement}

Specific engagement for Applied Learning Theories (ALT) was measured using the Applied Learning Theories Engagement (ALTEN) measure. According to Pare et al. (2019) [29], the measure contains 60 items: 30 items each for both the Rating Scale (ALTEN-RS) and the Engagement Checklist (ALTEN-CL). The ALTEN-RS checks the degree to which a student practices the theoretical concepts and tips covered in SSELECT and asks respondents to rate their practice on statements such as, "I follow a consistent format in note-taking.". Items are cumulatively scored and rated on a 5-point Likert scale varying from 1 to 5 , which correspond to "never" up to "always," respectively. Meanwhile, the ALTEN-CL consists of mostly closeended questions of differing formats (e.g., multiple-choice, rating) that ascertain ALT engagement in greater detail and produce nominal and ordinal data for demographic profiling. The 60-item instrument can measure overall engagement in Applied Learning Theories, which can be factored into dimensions of engagement with enhancing study strategies, test-taking attributes, and self-care practices. In terms of psychometrics, the ALTEN is reported to have good reliability and validity. Among other things, the ALTEN has presented a Cronbach's alpha of 0.84 for total ALT engagement and a Pearson $r$ range of 0.76 to 0.93 (significant at $p<0.01$ ) for the subscales as well as good item validity [29].

\subsection{Procedures}

The Ethics Review Committee of the Angeles University Foundation has approved the conduct of this study. The data gathering for the present research has been conducted in five (5) phases via online administration. Data collection for Phase 1 has been completed in A.Y. 2019-2020, while the students were attending their Applied Learning Theories (SSELECT) classes. Google Forms served as the primary means of disseminating the research instruments, and it was composed of three sections.

The first section of each Google Form contained the Informed Consent Form, which outlined the purposes of the study, the possible risks, and benefits, maintaining confidentiality, the procedures that participants will undergo in the study, and the voluntary nature of their participation as well as the contact information of the researchers. The respondents were encouraged to read the page contents. They were required to click on a button to signify that 
they have read and understood the terms and conditions written in the Informed Consent Form and that they were voluntarily participating. Otherwise, they could withdraw by closing the Google Form without answering. They could also withdraw participation after answering the survey by contacting their professors and providing their ID numbers so the researchers can erase their data entries.

The second section of each Google Form included the demographic profiling section. As stated in the Informed Consent form, respondents were required to provide personal information, including their student ID number, complete name, gender, college, course/programme, type of school previously attended, and the previous school's name. Such entries were used to identify the target population's demographic profile and assist in the discussion and interpretation of all succeeding results of the study.

The last part of each Google Form was the survey proper. Participants answered research instruments with questions intending to measure psychological well-being, student engagement, and ALT engagement. A Google Sheet spreadsheet was generated per questionnaire, each containing the responses of the participants to serve as the comprehensive database of the current project. Prior to submitting their responses, participants were asked to recheck their answers and check if all given information was true and updated to the best of their knowledge.

\section{Results and Discussion}

The Google spreadsheet was generated, and the research instruments were scored according to the procedures stipulated for each scale. The data were then exported to IBM Statistical Package for the Social Sciences (SPSS) Statistics 22. Prior to the analyses, the data set was examined for missing items or data entry errors. Seven student responses were removed from the data set due to incomplete GWA resulting in a total of 1066 student responses for data analysis.

Means and standard deviations were computed for all study variables. The association between the total ALT instrument score and its three facets and GWA, USEI total score, and PERMA total score were analyzed using Pearson's r; Coefficients of determination were also computed. Table 1 shows the results of the analyses. The total ALT engagement score was found to be positively associated with GWA, USEI, and PERMA. As for its facets, only ALTSS and ALT-TTA were found to be associated with GWA. All three facets were positively related to USEI and PERMA. Scores from the ALT engagement instrument were found to have the strongest association with USEI and weakest with GWA.

Table 1. Means and standard deviations, and correlation coefficients of the ALT engagement instrument with GWA, USEI, and PERMA

\begin{tabular}{lllllllll}
\hline & \multicolumn{3}{c}{ GWA } & \multicolumn{3}{c}{ USEI } & \multicolumn{3}{c}{ PERMA } \\
& $\mathrm{M}$ & $\mathrm{SD}$ & $\mathrm{r}$ & $\mathrm{r}^{2}$ & $\mathrm{r}$ & $\mathrm{r}^{2}$ & $\mathrm{r}$ & $\mathrm{r}^{2}$ \\
\hline GWA & 88.74 & 3.96 & & & & & & \\
USEI & 58.47 & 6.845 & & & & & & \\
PERMA & 168.14 & 22.545 & & & & & & \\
ALT-EN & 107.81 & 12.107 & $.125^{* *}$ & $.16^{*}$ & $.478^{* *}$ & .228 & $.350^{* *}$ & .122 \\
ALT-SS & 63.76 & 7.51 & $.155^{* *}$ & $.024^{*}$ & $.448^{* *}$ & .201 & $.280^{* *}$ & .078 \\
ALT-TTA & 22.75 & 3.413 & $.106^{* *}$ & $.011^{*}$ & $.459 * *$ & .211 & $.345^{* *}$ & .119
\end{tabular}




\begin{tabular}{lllllllll} 
ALT-SCP & 21.3 & 3.273 & -.003 & .000 & $.260 *$ & .068 & $.292 * *$ & .085 \\
\hline Notes & $*$ significant at $<.05$ & & & & & \\
& $* *$ significant at $<.00$ & & & &
\end{tabular}

The study's findings suggest that ALT as a course for freshman orientation and academic success is associated with students' academic achievement, well-being, and student engagement. As most freshmen success courses, ALT was designed to equip students with the knowledge, skills, and abilities necessary to transition to College and overcome their challenges in their first year of college [31]. Although there are a number of researches that looked into the contribution of freshmen success courses to students' observed growth and success, the findings are varied, from having positive results to no associations at all. A meta-analysis of the effectiveness of first-year seminars supports the current study's result in that first-year success courses have only a minimal positive effect on the first-year GPA [31]. Several relatively stable factors, such as cognitive ability and personality, have impacted academic achievement [25]. Consequently, ALT's short-term intervention as a freshman orientation and academic success course is not enough to account for academic achievement. It may be wise to consider long-term, continuous, and multi-faceted intervention programs to promote students' academic success [37].

Kahu and Nelson [21] provided a framework of student engagement that proposes that engagement is at the heart of an educational interface formed by the interplay between student characteristics and university practices. In the current study, ALT engagement is positively associated with student engagement. This association means while the students were engaged in ALT, there is an increase in the likelihood that they were engaged at the university level. Using Kahu and Nelson's framework [21], student engagement is facilitated by the interplay of the Institution and its students and the broader geopolitical context where the student is situated. It was emphasized that the University's role is to design curricula that are flexible to facilitate student and University interaction [24]. ALT was included in the different university programs' curricula to allow students to be more engaged in learning while developing their well-being. The inclusion of ALT is the University's response to deepening first-year students' engagement. Interestingly, student success courses have been known to enhance self-efficacy and confidence, and belonging, strengthening students' resolve to stay on their academic path, which is an indicator of engagement $[23,28]$. Factors such as self-efficacy, belonging, and well-being have been identified as mediating mechanisms that increase or decrease student engagement likelihood [21] but were not measured in the current research.

The current study also showed a significant positive association between ALT engagement and well-being. The relationship between constructs means that as students engaged in ALT, there is a corresponding increase in students' well-being. Student orientation courses that incorporated wellness were related to student wellness changes [14]. Since most first-year students go through transitional and developmental experiences, activating protective factors such as well-being is beneficial [39]. The results of the recent study conducted by Chatterjee \& Jethwani [13] supported the claim of prior research that self-care is strongly linked with wellbeing - that the more a person practices self-care, the more that his or her well-being increases. Hence, it was intentional on the part of the designers of the ALT syllabus to include self-care practices that boost well-being. This strategy is beneficial in the long run as enhancing students' positive developmental assets may prove to be an excellent measure to enhance students' academic success in higher education [39].

The long-term consequences and the course's effectiveness have yet to be established in the project's succeeding phases. Although the results can help claim ALT as an example of good practice in the University's context, several limitations should be noted: Primarily, students' 
GWA represents academic achievement, which is a limited representation of academic success. Other facets of academic success will be measured in the different stages of the research. Also, the current measure of engagement is limited only to the tri factorial structure of student engagement. However, mediating factors that influence student engagement were not explicitly measured in this study. Also, well-being in the study only represented total score and did not look into specific elements that make up well-being.

As the research continues, a system of evaluation of the in-class activities, readings, discussions, and topics of the course will be put in place to determine which is most effective. Specifically, there may be a need to recalibrate the topic of self-care practices to ensure that the learning goals and objectives are clearly articulated. Equally important is that as students' progress through their degree program, it might be beneficial to integrate other educational success initiatives to reinforce what they learned in their first year at the University.

\section{Conclusions}

The University's decision to offer Applied Learning Theories as a General Education Elective was based on the impetus of leveraging data to develop targeted and focused intervention programs for students. Findings of the present study lend support to the premise that a subject that is anchored on research-based strategies and high impact educational practices will bridge the gap between college eligibility and college readiness. Results showed that as students learn and engage in the subject, they appear to become more academically and cognitively engaged. Easing from familiarity to eventual mastery of the topics facilitates collaboration with their teachers and classmates, hopefully leading to a greater sense of belongingness to the University. With the introduction of concepts such as the growth mindset, optimism, resilience, and mindfulness, among many others, students can develop positive emotions, sustain interest in challenging tasks, and inspire them to find their meaning and purpose. Providing these essential experiences to students may fortify their disposition to become academically successful.

\section{References}

[1] Abulencia A 2016 The unraveling of K-12 program as an education reform in the Philippines South East Asian Journal for Youth, Sports \& Health Education 1(2) pp. 229-240

[2] Acosta I C and Acosta A S 2016 From anxiety to reality: understanding the lived-experiences of higher education institutions' faculty on the impact of the K-12 implementation in the Philippine Education System International Journal of Education and Research 4(3) pp. 59-72

[3] Adams, W., Franklin, D., \& Gulick, D. 2011 Remediation: Higher Education's Bridge to Nowhere. p.4

[4] Adler A 2017 Positive education: Educating for academic success and for a fulfilling life. Papeles Del Psicologo 38(1) pp. 50-57

[5] Assunção H, Lin S W, Sit P S, Cheung K C, Harju-Luukkainen H, Smith T, Maloa B, Campos J Á D B, Ilic I S, Esposito G, Francesca F M and Marôco J 2020 University student engagement inventory (USEI): transcultural validity evidence across four continents. Frontiers in Psychology, 10(January) pp. $1-12$

[6] Bean J and Eaton S B 2001 The psychology underlying successful retention practices. Journal of College Student Retention 3(1) pp. 73-89

[7] Beauvais A M, Stewart J G, DeNisco S and Beauvais J E 2014 Factors related to academic success among nursing students: a descriptive correlational research study. Nurse Education Today, 34(6) pp. 918-923 
[8] Boatman A, and Long B T 2018 Does remediation work for all students? how the effects of postsecondary remedial and developmental courses vary by level of academic preparation. Educational Evaluation and Policy Analysis 40(1) pp. 29-58.

[9] Brownel, J. E., \& Swaner, 2009. Outcomes of High-Impact Educational Practices: A Literature Review. Diversity \& DemocracyAssociation of American Colleges and Universities [Internet] 12(2). Available from https://www.aacu.org/publications-research/periodicals/outcomes-high-impacteducational-practices-literature-review

[10] Butler J and Kern M L 2016 The PERMA-Profiler: a brief multidimensional measure of flourishing. International Journal of Well-being 6(3) pp. 1-48.

[11] Caprara G V, Vecchione M, Alessandri G, Gerbino M and Barbaranelli C 2011 The contribution of personality traits and self-efficacy beliefs to academic achievement: a longitudinal study. British Journal of Educational Psychology 81(1) pp. 78-96

[12] Caruth G D 2018 Student engagement, retention, and motivation: assessing academic success in today's college students Participatory Educational Research 5(1) pp. 17-30

[13] Chatterjee, S., \& Jethwani, J.2020 A study of The Relationship between Mindful Self-Care and Subjective Well-Being among College Students and Working Professionals International Journal of Innovative Research and Teaching, 7(2) pp.417-425

[14] Choate L H and Smith S L 2003. Enhancing development in 1st-year college student success courses: a holistic approach The Journal of Humanistic Counseling, Education and Development, 42(2) 178-193

[15] Culver K C and Bowman N A 2018 Is what glitters really gold? a quasi-experimental study of first-year seminars and college student success. Research in Higher Education 61 pp. 167-196.

[16] Fredricks J A, Filsecker M and Lawson M A 2016 Student engagement, context, And adjustment: addressing definitional, measurement, and methodological issues. Learning and Instruction, 43 pp. 1-4

[17] Fredrickson B L and Branigan C 2005 Positive emotions broaden the scope of attention and thought-action repertoires. Cognition and Emotion, 19(3) pp. 313-332

[18] Gunuc S 2014 The relationships between student engagement and their academic achievement. International Journal on New Trends in Education and Their Implications, 5(4) pp. 216-231.

[19] Heiman, M. (2010). Solving the problem: Improving Retention in Higher Education Academic Leadership: The Online Journal 8(1) Article 28 Available from http://fsu/alj/vol8/iss1/28

[20] Kahu E R, Picton C and Nelson K 2020 Pathways to engagement: a longitudinal study of the first-year student experience in the educational interface Higher Education 79(4) pp. 657-673

[21] Kahu, E R, and Nelson K 2017 Student engagement in the educational interface: understanding the mechanisms of student success Student engagement in the educational interface Higher Education Research \& Development 0(0) pp. 1-14

[22] Kessler R C, Berglund P, Demler O, Jin R, Merikangas K R and Walters E E 2005 Lifetime prevalence and age-of-onset distributions of World Psychiatry Official Journal of the World Psychiatric Association WPA 62(June 2005) pp. 593-602.

[23] Kimbark K, Peters M L and Richardson T. 2017 Effectiveness of the student success course on persistence, retention, academic achievement, and student engagement. Community College Journal of Research and Practice 41(2) pp. 124-138

[24] Komarraju M, Ramsey A and Rinella V 2013 Cognitive and non-cognitive predictors of college readiness and performance role of academic discipline Learning and Individual Differences $24 \mathrm{pp}$. 103-109

[25] Kuncel N R, Ones D S, and Sackett P R 2010 Individual differences as predictors of work, educational, and broad life outcomes Personality and Individual Differences 49(4) pp. 331-336

[26] Lee J S 2014 The relationship between student engagement and academic performance: is it a myth or reality? Journal of Educational Research 107(3) pp. 177-185

[27] Maroco J, Maroco A L, Campos J A D B and Fredricks J University student's engagement: development of the university student engagement inventory (usei) psicologia: reflexão e crítica, 29(21) 
[28] O'Gara L, Karp M M and Hughes K L 2009 Student success courses in the community college: an exploratory study of student perspectives Community College Review 36(3) pp. 195-218

[29] Pare E L L, Reyes M S M and Dimacuha Q T K A 2019 Development and validation of a measure for student engagement in applied learning theories (alt) class among first-year university students [Undergraduate paper] Angeles City:Angeles University Foundation;2019.

[30] Pedrelli P, Nyer M, Yeung A, Zulauf C and Wilens T 2015 College students: mental health problems and treatment considerations Academic Psychiatry 39(5) pp. 503-511

[31] Permzadian V and Credé M 2016 Do first-year seminars improve college grades and retention? a quantitative review of their overall effectiveness and an examination of moderators of effectiveness Review of Educational Research 86(1) pp. 277-316

[32] Seligman, M. 2018 PERMA and the building blocks of well-being. Journal of Positive Psychology, 13(4), 333-335

[33] Seligman M E P, Ernst R M, Gillham J, Reivich K and Linkins M 2009 Positive education: positive psychology and classroom interventions Oxford Review of Education 35(3) pp. 293-311

[34] Tamayao A, Vecaldo R, Asuncion J E, Mamba M, Paat F M and Pagulayan E 2020 Design and validation of the college readiness test (crt) for filipino $\mathrm{k}$ to 12 graduates International Journal of Higher Education 9(2) pp. 209-224

[35] Um E R, Plass J L, Hayward E O and Homer B D 2012 Emotional design in multimedia learning Journal of Educational Psychology 104(2) pp. 485-498

[36] Valenzuela D F O Should I Stay Or Should I Go? A Study on the Impact of K-12 on the Perspectives and Future Plans of Grade 12 Students upon Graduation from Senior High in Selected Schools in Cubao, Quezon City. [Undergraduate thesis] Manila: University of the Philippines; 2018.

[37] Wibrowski C R, Matthews W K and Kitsantas A 2017 The role of a skills learning support program on first-generation college students' self-regulation, motivation, and academic achievement: a longitudinal study Journal of College Student Retention: Research, Theory, and Practice 19(3) pp. 317-332

[38] York T T, Gibson C and Rankin S 2015 Defining and measuring academic success Practical Assessment, Research and Evaluation 20(5) pp. 1-20

[39] Yu L, Daniel D T and Zhu X 2018 The influence of personal well-being on learning achievement in university students over time: mediating or moderating effects of internal and external university engagement Frontiers in Psychology 8(JAN) pp. 1-16 